\title{
Manganese dioxide nanoparticles-silver-Y zeolite as a nanocomposite catalyst for the decontamination reactions of $O, S$-diethyl methyl phosphonothiolate
}

\author{
K. Dastafkan $\cdot$ M. Sadeghi $\cdot$ A. Obeydavi
}

Received: 26 April 2014/Revised: 12 September 2014/ Accepted: 22 October 2014/Published online: 11 November 2014 (C) Islamic Azad University (IAU) 2014

\begin{abstract}
The decontamination reactions of $O, S$-diethyl methyl phosphonothiolate, as an agricultural organophosphorous pesticide onto $20 \mathrm{wt} \%$ loaded manganese dioxide nanoparticles-silver-Y zeolite as a nanocomposite catalyst in different solvents, were evaluated and monitored by means of gas chromatography-flame ionization detector and gas chromatography-mass spectrometry. Prior to the reaction, the catalyst was synthesized in three steps: at first, sodium-Y zeolite was prepared by hydrothermal method; then, silver-Y zeolite was prepared from sodium-Y zeolite using ion exchange procedure; and finally, manganese dioxide nanoparticles were synthesized by in situ impregnation method by pouring the pre-prepared silver-Y zeolite into manganese(II) nitrate solution and loaded as $20 \mathrm{wt} \%$ onto silver-Y zeolite structure. The formation of the synthesized units and final nanocomposite catalyst was verified through scanning electron microscopy, X-ray diffraction, atomic absorption spectrometry and Fourier transform-infrared spectroscopy techniques. Gas chromatography chromatograms showed that $O, S$-diethyl methyl phosphonothiolate was decontaminated perfectly by the catalyst in $n$-heptane solvent after $8 \mathrm{~h}$, at room temperature, while chloroform and isopropanol solvents and other reaction times gave lower decontamination results. Moreover, gas chromatography-mass spectrometry chromatograms confirmed the formation of ethyl methyl phosphonic
\end{abstract}

K. Dastafkan ( $\square)$

Young Researchers and Elite Club, Karaj Branch, Islamic Azad

University, Karaj, Iran

e-mail: kamrandastafkan@gmail.com

M. Sadeghi · A. Obeydavi

Young Researchers and Elite Club, Ahvaz Branch, Islamic Azad

University, Ahvaz, Iran acid as a major and final product, which exemplifies the role of hydrolysis reaction during the degradation progress.

Keywords Decontamination $\cdot O, S$-diethyl methyl phosphonothiolate $\cdot$ Manganese dioxide nanoparticlessilver-Y zeolite · Nanocomposite catalyst · Degradation . Ethyl methyl phosphonic acid

\section{Introduction}

Pesticides are among the most important environmental pollutants used in intensive agriculture and are currently a matter of major concern. High interference of pesticides with nearby communities overlaps with ecosystem due to their wide use in agricultural crops, residential and commercial buildings, ornamental gardens and plants (PadronSanz et al. 2005). The exposure of water resources to pesticides has acute effects on aquatic species, terrestrial species and people who reside in the vicinity of them (Shen et al. 2007). Organo-phosphorous compounds (OPs) form a large group of chemicals used for protecting crops and livestock and as warfare agents over the past 60 years (Munro et al. 1999). Synthetic OPs are the most widely used pesticides that have released unacceptable and widespread levels of environmental residues across different populations (Howard et al. 1990). Their partial persistence in the environment and their possible incorporation into the food chain provoke poisoning as a result of consuming contaminated liquids or foods, inhalation and also poisoning through the skin (Paukku et al. 2008). The accumulation of OPs in body produces toxins and involves various disorders such as proliferation of breast cancer cells, adverse reproductive outcomes, peripheral neuropathy, neurobehavioral disorders, impaired immune functions 


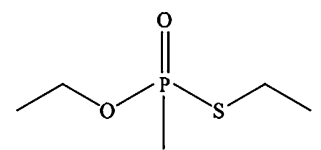

Fig. 1 The chemical structure of OSDEMP

and allergic sensitization reactions, particularly of the skin (Barata et al. 2004; Al-Qurainy and Abdel-Megeed 2009; Moussavi et al. 2013). The adverse short-term effects of exposure to these chemicals have been mostly studied in the nervous system, that is their primary target, but there is a growing concern about their possible toxic effects in nontarget tissues and long-term (chronic) effects that have not been studied in such detail (Singh et al. 2011). OPs are mostly liposoluble, and their primary mechanism of toxicity, that is to say, their function as inhibitors of acetyl cholinesterase (AChE) enzyme that leads to the accumulation of acetylcholine in vital organs, which consequently interferes with muscular responses and eventually results in death is well studied (Diurak and Kazanicif 2001). Neurological dysfunction caused by intentional or accidental overdoses through exposure to OPs is most frequently assessed by the measurement in AChE activity (Munro et al. 1999; Singh et al. 2011). Therefore, the determination followed by degradation (decontamination) of OPs is urgent for environmental risk assessment. Structureactivity relationships of OPs are esters, phosphoric acid and its derivatives. The general chemical structure of an organo-phosphate comprises a central phosphorus atom $(\mathrm{P})$ and the characteristic phosphoric $(\mathrm{P}=\mathrm{O})$ or thiophosphoric $(\mathrm{P}=\mathrm{S})$ bond.

$O, S$-diethyl methyl phosphonothiolate (OSDEMP) as an organo-phosphorous pesticide or a chemical warfare simulant makes inevitable threats to the environment and biological systems of the people who make contact, hence causing health hazards. The vicinity of OSDEMP to nerve agents leads to the inhibition of the activity of $\mathrm{AChE}$ enzyme through phosphorylation of the serine residue in its active site (Singh et al. 2011). The chemical structure of OSDEMP with the molecular formula of $\mathrm{C}_{5} \mathrm{H}_{13} \mathrm{PO}_{2} \mathrm{~S}$ is illustrated in Fig. 1.

To control such hazards, different methodologies have been reported so far. One of the most known and longterm-used methods is liquid detoxification which utilizes chemicals including oxidants such as $m$-chloroperoxybenzoic acid, magnesium monoperoxyphthalate, potassium persulfate, oxon, sodium hypo-chlorite and hydrogen peroxide $\left(\mathrm{H}_{2} \mathrm{O}_{2}\right)$ (Wagner et al. 2000; Bartram and Wagner 2003; Singh et al. 2011). However, these materials are quite toxic and have disadvantageous results for the environment. Therefore, researching for finding the substitutions that have no hazardous side effects is of great importance. Adsorption technology intended for the removal of environmental decontamination (Gupta et al. 2010a, b, 2011; Gupta and Nayak 2012; Gupta et al. 2013) has been useful in this area and developed as a substitution for liquid detoxification.

Recent interests have been conducted toward the adsorption and degradation of organo-phosphorous compounds by molecular sieves such as sodium-Y $(\mathrm{NaY})$ and silver-Y (AgY) zeolites (Wagner and Bartram 1999; Patterson 2006; Stout et al. 2007). Zeolites belong to a large family of alumino-silicates constituted by corner-like $\mathrm{TO}_{4}$ tetrahedral units ( $\mathrm{T}$ represents either $\mathrm{Al}$ or $\mathrm{Si}$ ) which adopt a remarkable variety of crystalline structures containing channels and/or cavities with different dimensions. Aluminum-containing zeolites possess a negatively charged framework which results from $\mathrm{AlO}_{2}{ }^{-}$units replacing natural $\mathrm{SiO}_{2}$ units. The negative charge is balanced by an equivalent number of extra-framework cations. Y-type zeolite is the synthetic form of faujasite family and has a $\mathrm{Si} / \mathrm{Al}$ ratio between 2 and 5 (Barlocher et al. 2001; Patterson 2006; Stout et al. 2007) which ensues from its low aluminum content. For promoting the practicality of Y-type zeolite, often ionic exchange substitution of $\mathrm{Na}$ by other cations such as $\mathrm{Mg}, \mathrm{Cu}, \mathrm{Zn}$ and $\mathrm{Ag}$ is preceded (Huang 1974; Feeley and Sachtler 1991; Seidel et al. 1998; Elzey et al. 2008; Oliveira et al. 2009). One of the important forms of zeolites resulting from ion exchange procedure is $\mathrm{AgY}$ zeolite. Cation $\mathrm{Ag}^{+}$as a significant reagent is applied in many catalytic procedures (Huang 1974; Qi et al. 2007; Wong et al. 2008).

Several reports have been published in the literature concerning the detoxification applications of zeolites. Among them, the use of sodium X-type faujasite zeolite for the decomposition of dimethyl methylphosphonate and in adsorption chemistry of organophosphates (Yang et al. 2006; Sambur et al. 2008; Meng et al. 2011), adsorption and thermal reaction of dimethyl methylphosphonate onto nano-crystalline sodium-Y-type zeolite (Knagge et al. 2006; Stout et al. 2007), adsorption of diethyl-m-toluamide onto HY zeolite (Trouve et al. 2012) and degradation of insecticide methomyl over the surface of Fe-doped ZSM-5 zeolite (Tomašević et al. 2010) are worthy of notice.

From the point of view of surface chemistry, adsorption and degradation reactions of organo-phosphorous pesticides are also viable on the surface of metals and metal oxides. The accessible amount of bounding energy, the number of existing atoms on the surface and the option of surface functionalization that provides proper functional groups and sufficient amount of charge and density make it possible to apply the surface of metals and metal oxides as an alternative to the adsorption and degradation of organo- 
phosphorous pesticides. Studies have found metal oxides such as $\mathrm{CeO}_{2}, \mathrm{SiO}_{2}, \mathrm{Al}_{2} \mathrm{O}_{3}, \mathrm{MgO}, \mathrm{Fe}_{2} \mathrm{O}_{3}$ and $\mathrm{La}_{2} \mathrm{O}_{3}$ with submicron-sized particles that convert toxic pesticides into non-toxic or less toxic products. Several types of reactions occur on the surface of such metal oxides including catalytic oxidation, nucleophile-assisted substitution, catalytic elimination and hydrolysis. However, the reactions on the surface of these metal oxides are rather slow, and massive quantities of pollutants are found to remain within the metal oxide matrix even after several hours of use. One main technical hurdle is low selectivity toward a target phosphonate molecule for the interaction with adsorption sites on the surface (Kanan and Tripp 2001). For the oxidation approach, metal oxides are applied to form organometallic complexes in the presence of an oxidant such as hydrogen peroxide. One reason for slow oxidation could be the decomposition of peroxide by the metallic catalyst forming molecular oxygen, which then escapes from the reaction mixture and deactivates the catalyst. Also on these oxides, the nucleophilic substitution and hydrolysis reactions at room temperature proceeding through surface bonds between hydroxyl groups and electron acceptor metal species with the $\mathrm{P}=\mathrm{O}$ group have been reported to take place too slowly (Yang et al. 1992; Wagner et al. 1999; Mitchell et al. 2003).

In order to obviate these limits, the application of nanomaterials (NMs) opens the narrow window of slow rate and incomplete reaction. Several papers introducing nanomaterials as adsorbents and catalysts for the removal of organo-phosphorous pesticides, such as $\mathrm{Fe}_{3} \mathrm{O}_{4}$ nanoparticles-C18 nano-magnetic composite (Shen et al. 2007), oxidized carbon nanotubes (Li et al. 2009), polypyrrole/ polyamide electrospun-based nanofibers (Bagheri et al. 2012) and $\mathrm{ZnO}$ nanoparticles (Chen et al. 2012) have been published. Due to the large surface area, nanomaterials have enhanced capacity to strongly adsorb pesticides from affected surfaces and make them safe to operate. Once trapped in the pores of the nanoadsorbent, pesticides undergo reactions facilitated by reactive sites that are integrated with nanomaterials (Rusu and Yates 2000; Mahato et al. 2010; Prasad 2010).

In fact, certain interactions of alkyl phosphonate compounds with various $\mathrm{Al}, \mathrm{Si}, \mathrm{Na}$ and $\mathrm{Ag}$ units and also other loaded metal oxides including adsorption reactions of phosphonates with surface oxygen atoms, Bronsted acid -OH groups and metallic Lewis acid sites and also nucleophilic substitution into alkyl phosphonates occur to provoke the decontamination procedure. As for zeolites, adsorption of toxic agents followed by degradation reaction performs thoroughly due to high adsorption capacity provided by both intrinsic porous structure of aluminumsilicate network and external functionalization with a potential catalytic reactive cation. Individually, intrinsic compositions, apparent sizes and extrinsic surface structures of nanoparticles direct a number of factors that enhance the selectivity and sensitivity of the method, namely high surface area, active Bronsted and Lewis sorption sites and chemical activity with which the adsorption and subsequent catalytic degradation may proceed (Yang et al. 2006; Khajeh et al. 2013). The combination of zeolites and nanomaterials causes solid catalysts in which the high surface area of nanomaterials and the adsorbent capacity provided by zeolites cooperate to increase the efficiency of the catalytic process (Khatamian et al. 2011). In this work, we have synthesized $\mathrm{AgY}$ zeolite and manganese dioxide $\left(\mathrm{MnO}_{2}\right)$ nanoparticles by $\mathrm{AgNO}_{3}$ and $\mathrm{Mn}\left(\mathrm{NO}_{3}\right)_{2}$ as silver and manganese precursors and characterized the final nanocomposite in which $\mathrm{MnO}_{2} \mathrm{NPs}$ were loaded as 20 weight percent (wt\%) for the adsorption and degradation of OSDEMP. $\mathrm{Ag}^{+}$is the only noble mono-positive cation that forms mononuclear species with appreciable stability in aqueous solution. Besides, silver is known to have strong influence on the adsorption properties of zeolites. Silver possesses a strong affinity to complex with sulfur-containing ligands and the contact between zeolite with a silver content ranging between 10 and $40 \mathrm{wt} / \mathrm{wt} \%$ and the pesticide is persistent for a period of $1 \mathrm{~min}$ to 60 days at a temperature range of -30 to $50{ }^{\circ} \mathrm{C}$ (Bartram and Wagner 2003). The ion exchange process promotes better $\mathrm{Ag}$ dispersion down to nearly molecular level (Wong et al. 2008). In this case, $\mathrm{Ag}^{+}$has previously shown to promote the catalytic hydrolysis of diethyl ethylphosphonothiolate (DEEP) (Bartram and Wagner 2003). As an important functional metal oxide, $\mathrm{MnO}_{2}$ is among the most attractive representatives of inorganic materials exhibiting such a rich physical and chemical properties and wide applications in various fields such as catalysis, ion exchange, molecular adsorption, sensing and energy storage (Jiao and Frei 2010; Koivula et al. 2009; Liu et al. 2009; Wang et al. 2011; Yan et al. 2012). $\mathrm{MnO}_{2}$ is a very interesting material because of the diversity in its crystalline structure and high manganese valence (Shen et al. 1993; Cao and Suib 1994; Qi et al. 1999). The effect of different solvents and reaction times on the decontamination reaction at room temperature has been studied and the decontaminated product was separated and identified by gas chromatography-flame ionization detector (GC-FID) and gas chromatography-mass spectrometry (GC-MS) analyses. To the best of our knowledge, there are no papers reporting the application of $\mathrm{MnO}_{2} \mathrm{NPs}-\mathrm{AgY}$ zeolite composite catalyst for the decontamination of OSDEMP as an agricultural pollutant and the adsorptive catalyst is novel.

This work was carried out in Young Researchers and Elite Club, Ahvaz and Karaj branches, 2013 (JuneDecember). 


\section{Materials and methods}

\section{Materials}

All chemicals were of chemical grade and were used as received. Sodium hydroxide, aluminum trihydrate, sodium silicate, $\mathrm{KMnO}_{4}$, isopropanol, chloroform, $n$-heptane and $n$-octane were purchased from Merck (Merck, Darmstadt, Germany). $\mathrm{AgNO}_{3}$ and $\mathrm{Mn}\left(\mathrm{NO}_{3}\right)_{2} \cdot 6 \mathrm{H}_{2} \mathrm{O}$ were from Loba Chemie Co. (India). OSDEMP was obtained commercially from Sigma-Aldrich Co. (USA). Deionized water was used for the preparation of all solutions.

\section{Instrumentation}

The morphology and the size of the prepared nanocomposite catalyst were perused via SEM micrographs using a scanning electron microscope (SEM, LEO-1530VP). The powder X-ray diffraction (XRD) patterns of the samples were recorded using a Philips diffractometer equipped with a $\mathrm{Cu} \mathrm{K} \alpha$ radiation and a wavelength of $1.54056 \AA$ (30 mA and $40 \mathrm{kV}$ ). Intensity data were taken at $2 \theta$ ranged from $4^{\circ}$ to $90^{\circ}$ with a scanning speed of $2^{\circ} \min ^{-1}$. Weight percentages of the elements (silver and manganese) were measured by atomic adsorption spectrometry (AAS, Perkin Elmer, USA) coupled with a HGA 400 Programmer hybrid system and equipped with hollow cathode lamps at respective wavelength using an acetylene-air flame. The amounts of weight percentages were calculated through external standard method and interpolation within corresponding calibration curves. The IR spectra were scanned on a PerkinElmer model 2000 FTIR spectrometer (USA) in the wavelength range of $450-4,000 \mathrm{~cm}^{-1}$ using $\mathrm{KBr}$ pellets. The nanocomposite sample was blended and homogenized with dry potassium bromide in a 1:100 (m/m) ratio and prepared as pellet prior to IR measurement. A Varian Star 3400CX series gas chromatograph equipped with flame ionization detector (FID) and an OV-101CWHP $80 / 100$ silica capillary column $[30 \mathrm{~m} \times 0.25 \mathrm{~mm}$ inner diameter (i.d), $0.25 \mu \mathrm{m}$ film thickness] were used to monitor the decontamination reactions. The extracted product was analyzed by a HP-Agilent gas chromatography-mass spectrometry equipped with a fused-silica capillary column [DB $1701,30 \mathrm{~m} \times 0.25 \mathrm{~mm}$ inner diameter (i.d), $0.25 \mu \mathrm{m}$ film thickness]. The GC conditions used were as follows: The column temperature was initially held at $60{ }^{\circ} \mathrm{C}$ for $6 \mathrm{~min}$ and programmed at $20^{\circ} \mathrm{C} \mathrm{min}{ }^{-1}$ to $200{ }^{\circ} \mathrm{C}$ to reach the final temperature that was then held for $13 \mathrm{~min}$. The injector, MS quad and source temperatures were fixed at 60,200 and $230{ }^{\circ} \mathrm{C}$, respectively. Helium (99.999\% purity) was selected as the carrier gas with the flow rate of $1 \mathrm{~mL} \mathrm{~min}{ }^{-1}$.
Synthesis of NaY zeolite by hydrothermal method

Ten grams of sodium hydroxide $(\mathrm{NaOH})$ was dissolved in $30 \mathrm{~mL}$ of deionized water and rapidly heated to $100{ }^{\circ} \mathrm{C}$ under vigorous stirring. Near the boiling point, $9.75 \mathrm{~g}$ of aluminum trihydrate was suddenly added to $\mathrm{NaOH}$ solution. Then, $10 \mathrm{~mL}$ of this solution was mixed with $61.2 \mathrm{~mL}$ of deionized water, and further $5.9 \mathrm{~g}$ of $\mathrm{NaOH}$ was dissolved in the resulting solution (solution A). Twenty-two grams of sodium silicate was mixed and dissolved in $61.2 \mathrm{~mL}$ of deionized water containing $5.9 \mathrm{~g}$ of $\mathrm{NaOH}$ (solution B). Solution A was slowly added to the solution B and the resulting mixture was well agitated for $30 \mathrm{~min}$. The mixture was transferred to a stainless steel autoclave lined with PTFE (Teflon) and kept in a static air oven at $90{ }^{\circ} \mathrm{C}$ for $8 \mathrm{~h}$. The crystalline powder was filtered and washed with deionized water three times until the $\mathrm{pH}$ of the washing solution was equal to that of the deionized water. Finally, the powder was dried in an oven at $100{ }^{\circ} \mathrm{C}$ (Rasouli et al. 2012a, b).

Preparation of AgY zeolite by ion exchange method

In a typical preparation procedure, $2.2 \mathrm{~g}$ of the synthesized $\mathrm{NaY}$ zeolite calcined at $400{ }^{\circ} \mathrm{C}$ for $3 \mathrm{~h}$ in a furnace. The calcined $\mathrm{NaY}$ zeolite was then added to $50 \mathrm{~mL}$ of a $0.15 \mathrm{M}$ $\mathrm{AgNO}_{3}$ solution, and the mixture was magnetically stirred at $60{ }^{\circ} \mathrm{C}$ for $5 \mathrm{~h}$ to perform ion exchange process in which $\mathrm{Ag}^{+}$ions were replaced with $\mathrm{Na}^{+}$ions. The resulting zeolite was filtered and washed with deionized water in order to remove the excess salt ions, then dried at $110{ }^{\circ} \mathrm{C}$ for $16 \mathrm{~h}$. Finally, the clean and dry zeolite was calcined in a furnace for $4 \mathrm{~h}$ at $400{ }^{\circ} \mathrm{C}$ (Kim et al. 2006).

Preparation of $\mathrm{MnO}_{2} \mathrm{NPs}$ loaded onto $\mathrm{AgY}$ zeolite by impregnation method

The incorporation of $\mathrm{MnO}_{2} \mathrm{NPs}$ loaded onto $\mathrm{AgY}$ zeolite was accomplished by the impregnation method. At first, $1 \mathrm{~g}$ of $\mathrm{AgY}$ zeolite was poured into a $20 \mathrm{~mL}$ of $1 \mathrm{M}$ $\mathrm{Mn}\left(\mathrm{NO}_{3}\right)_{2}$ aqueous solution and stirred for $5 \mathrm{~h}$. Under continuous stirring, $50 \mathrm{~mL}$ of a $0.2 \mathrm{M} \mathrm{KMnO}_{4}$ solution was rapidly added to the mixture. $\mathrm{KMnO}_{4}$ is known among the strong oxidizing agents, in a way that, the color of the solution immediately turned to dark brown indicating the formation and precipitation of $\mathrm{MnO}_{2} \mathrm{NPs}$ through oxidation with $\mathrm{KMnO}_{4}$. The obtained sample was then dried at $100{ }^{\circ} \mathrm{C}$ for more than a night. At last, the product was treated by calcination for $4 \mathrm{~h}$ at $500{ }^{\circ} \mathrm{C}$ (Richter et al. 1999, 2002). The ionic equation of the reaction is as follows: 
Scheme 1 Proposed preparation procedures of $\mathrm{NaY}$ and $\mathrm{AgY}$ zeolites and

$\mathrm{MnO}_{2} \mathrm{NPs}-\mathrm{AgY}$ nanocomposite along with the decontamination process
Hydrothermal Method

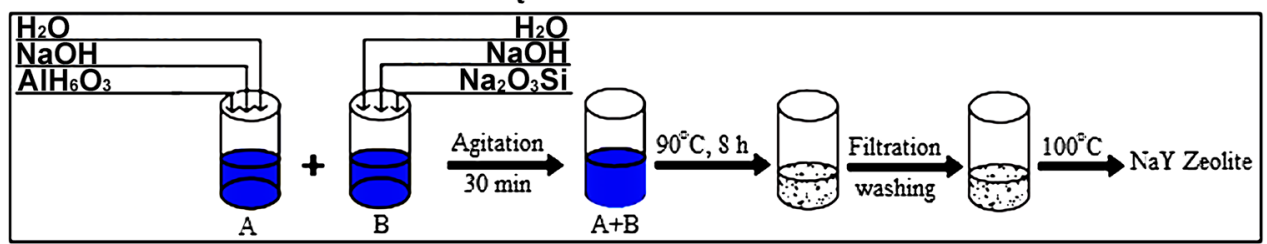

Ion Exchange Method

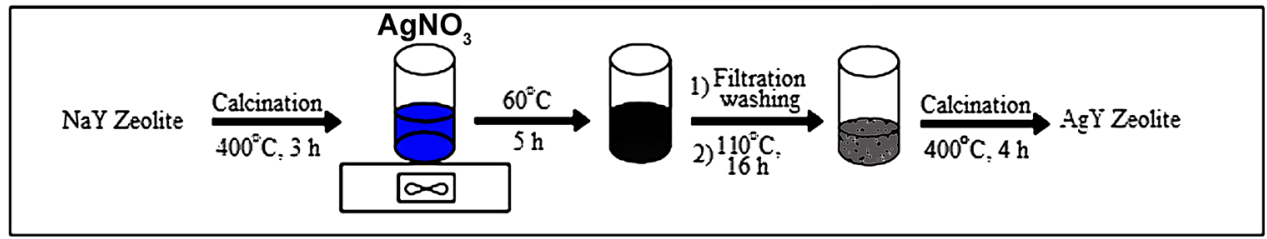

$\perp$

Impregnation Method
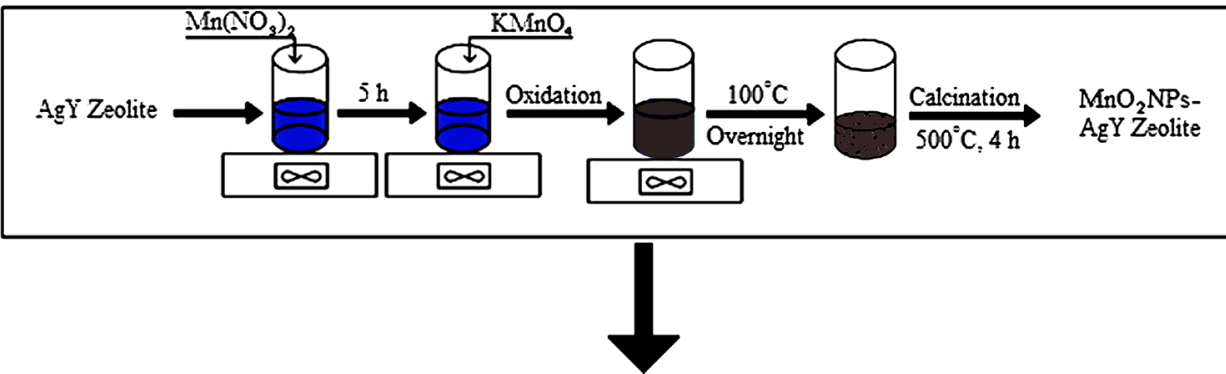

Decontamination Reaction

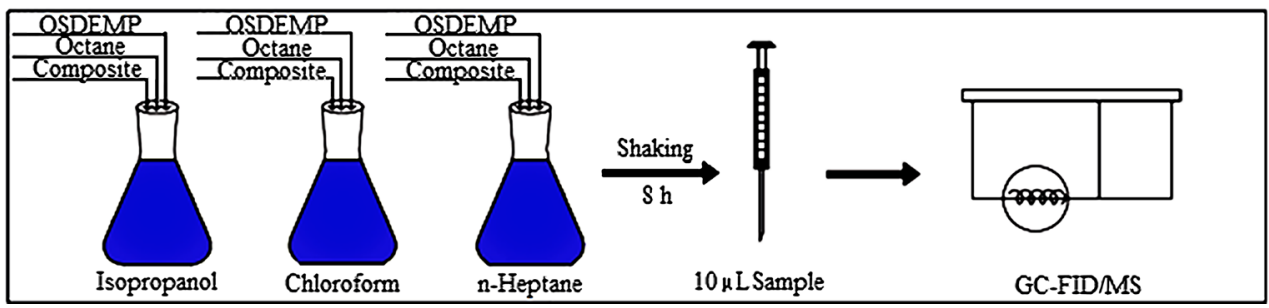

$3 \mathrm{Mn}^{2+}+2 \mathrm{MnO}_{4}^{-}+2 \mathrm{H}_{2} \mathrm{O} \rightarrow 5 \mathrm{MnO}_{2}+4 \mathrm{H}^{+}$

Decontamination reaction of OSDEMP on the surface of $20 \mathrm{wt} \% \mathrm{MnO}_{2} \mathrm{NPs}-\mathrm{AgY}$ zeolite

In order to investigate the reaction between the catalyst and OSDEMP, the samples were prepared according to the following procedure: $5 \mathrm{~mL}$ of each solvents (isopropanol, chloroform and $n$-heptane) representing the optimizing work solutions, $10 \mu \mathrm{L}$ of a $5: 1(\mathrm{v} / \mathrm{v})$ ratio of OSDEMP/ $\mathrm{H}_{2} \mathrm{O}$ sample, $10 \mu \mathrm{L}$ of $n$-octane as internal standard and $0.4 \mathrm{~g}$ of $\mathrm{MnO}_{2} \mathrm{NPs}-\mathrm{AgY}$ zeolite were added to a $100-\mathrm{mL}$ Erlenmeyer flask, which was later sealed to prevent the vaporization of the solvents. To achieve the maximum percentage of decontamination, all samples were shaken for $8 \mathrm{~h}$ under $\mathrm{N}_{2}$ atmosphere at room temperature. Finally, $10 \mu \mathrm{L}$ of all solution samples were extracted by a microsyringe and injected to GC and GC-MS instruments. The schematic of the preparation procedures and decontamination process is illustrated in Scheme 1.

\section{Results and discussion}

SEM study

The crystalline size and morphology of the as-synthesized samples were surveyed through magnification by 
SEM images (Fig. 2). Comparison between the morphologies of $\mathrm{NaY}$ and $\mathrm{AgY}$ zeolites and $20 \mathrm{wt} \%$ $\mathrm{MnO}_{2} \mathrm{NPs}-\mathrm{AgY}$ zeolite composite demonstrates the homogenous morphology of the structures. In addition to this, it shows that the cubic morphology and crystalline size of $\mathrm{NaY}$ zeolite are almost retained with ion exchange process that is indicated by SEM images in Fig. 2c, d, although it can be seen that the crystal structure of $\mathrm{MnO}_{2} \mathrm{NPs}-\mathrm{AgY}$ zeolite composite slightly changes as compared to support AgY zeolite (Fig. 2e, f). The presence of some bigger particles in the micrographs is attributed to the aggregation or overlapping of some smaller particles during nanocomposite preparation. In addition, SEM images obviously show that $\mathrm{MnO}_{2} \mathrm{NPs}$ have been dispersed and deposited on the external surface of $\mathrm{AgY}$ zeolite. The average crystalline size of $\mathrm{MnO}_{2} \mathrm{NPs}$ was illustrated to have nano-metric dimensions $(<100 \mathrm{~nm})$.
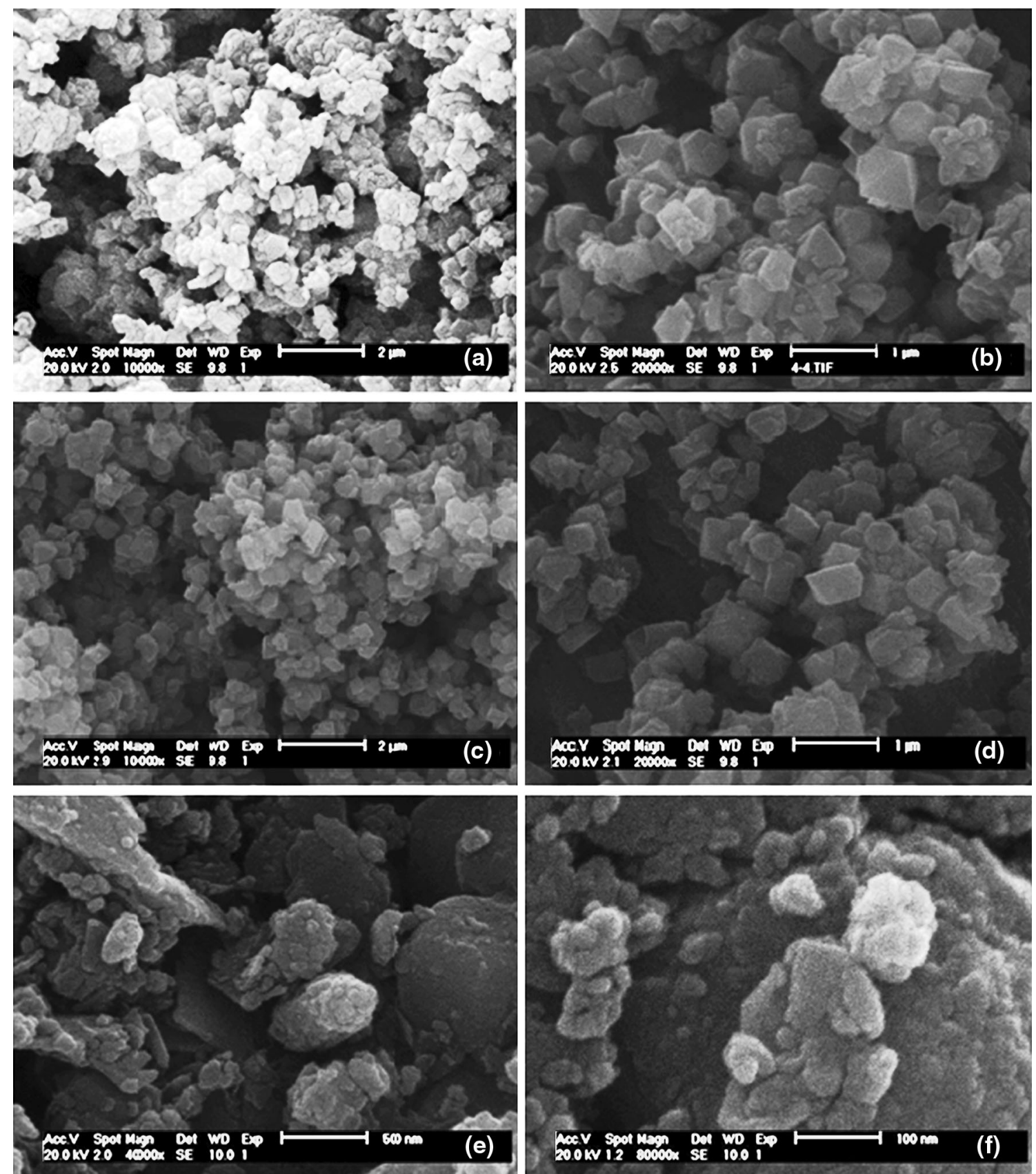

Fig. 2 The SEM images of the catalyst samples: a, b NaY zeolite, c, d $\mathrm{AgY}$ zeolite, e, f 20 wt $\% \mathrm{MnO}_{2} \mathrm{NPs}-\mathrm{AgY}$ zeolite with different resolutions 


\section{XRD patterns}

In Fig. 3, the XRD patterns of the understudy $\mathrm{NaY}$ and $\mathrm{AgY}$ zeolites and $20 \mathrm{wt} \% \mathrm{MnO}_{2} \mathrm{NPs}-\mathrm{AgY}$ zeolite composite are displayed. As seen from the patterns, eleven major and sharp peaks referring to $\mathrm{NaY}$ zeolite occurred at scattering angles $(2 \theta)$ of $6.00^{\circ}, 9.93^{\circ}, 11.64^{\circ}, 15.39^{\circ}, 17.39^{\circ}, 20.91^{\circ}, 24.56^{\circ}$, $27.35^{\circ}, 30.95^{\circ}, 34.20^{\circ}$ and $37.38^{\circ}$ corresponding to the diffraction planes of (111), (220), (311), (331), (511), (440), (444), (553), (660), (931) and (1022), respectively, which have been crystallized in cubic system and are in good agreement with those of $\mathrm{NaY}$ zeolite with the molecular formula of $\mathrm{Na}_{1.84} \mathrm{Al}_{2} \mathrm{Si}_{4} \mathrm{O}_{11.92} \cdot 7 \mathrm{H}_{2} \mathrm{O}$, the reference code (ICDD) of 00-038-0238, space group of $F$, and lattice size of $24.7560 \AA$. The structure was almost retained even after silver cation exchange in AgY zeolite. Meanwhile, synthesized $\mathrm{MnO}_{2} \mathrm{NPs}$ as guest material loaded as $20 \mathrm{wt} \%$ onto $\mathrm{AgY}$ zeolite as host material possesses a series of new peaks, which were obtained at $2 \theta$ of $19.50^{\circ}, 36.234^{\circ}, 44.04^{\circ}, 55.78^{\circ}$ and $64.52^{\circ}$ corresponding to the diffraction planes of (200), (210), (202), (212) and (203), respectively, that have been crystallized in the orthorhombic system (ICDD 00-0390375). No characteristic peaks related to the presence of impurities during silver cation substitution and manganese(IV) oxide loading were observed in the patterns. The peaks labeled as squares and triangles in Fig. 3c reveal the dispersion and deposition of $\mathrm{MnO}_{2} \mathrm{NPs}$ and $\mathrm{AgY}$ structure after nanoparticles loading, respectively, and also indicate a host-guest interaction between AgY framework and $\mathrm{MnO}_{2} \mathrm{NPs}$. A definite line broadening of the scattering pattern in Fig. $3 \mathrm{c}$ is a demonstration upon which the synthesized $\mathrm{MnO}_{2}$ particles are in nanoscale range. However, a small loss of crystallinity is observed in Fig. 3b, c, which could be interpreted by the dealumination of $\mathrm{AgY}$ zeolite and the prepared nanocomposite, probably associated with the situation of ion exchanged and the extra-framework cations. In the case of Fig. 3c, the impregnated $\mathrm{Mn}^{4+}$ ions interact with the aluminate sites within zeolite structure with a greater intensity than that of host cations $\left(\mathrm{Na}^{+}\right.$or $\left.\mathrm{Ag}^{+}\right)$. Totally, it can be concluded that with silver ion exchange in $\mathrm{NaY}$ zeolite and subsequent loading of $\mathrm{MnO}_{2} \mathrm{NPs}$ onto $\mathrm{AgY}$ zeolite, the structure of the zeolites is subjected to a small change. On the other hand, the capacity of the Y-type zeolite to keep the guest species is limited. Consequently, the adsorption of the guest cations as $\mathrm{Mn}^{4+}$ will stop if the capacity is full, and catalytic efficiency will decline. The introduced $\mathrm{MnO}_{2} \mathrm{NPs}$ were dispersed and deposited on the external surface of $\mathrm{AgY}$ zeolite; however, some particles may be subjected to relative aggregation that occurs during the nanocomposite synthesis process and become too large to perch on the structure. Thus, high $\mathrm{MnO}_{2} \mathrm{NPs}$ loading will cause structural damage to the zeolite. The crystalline size of $\mathrm{MnO}_{2} \mathrm{NPs}$ was also investigated via XRD measurement and
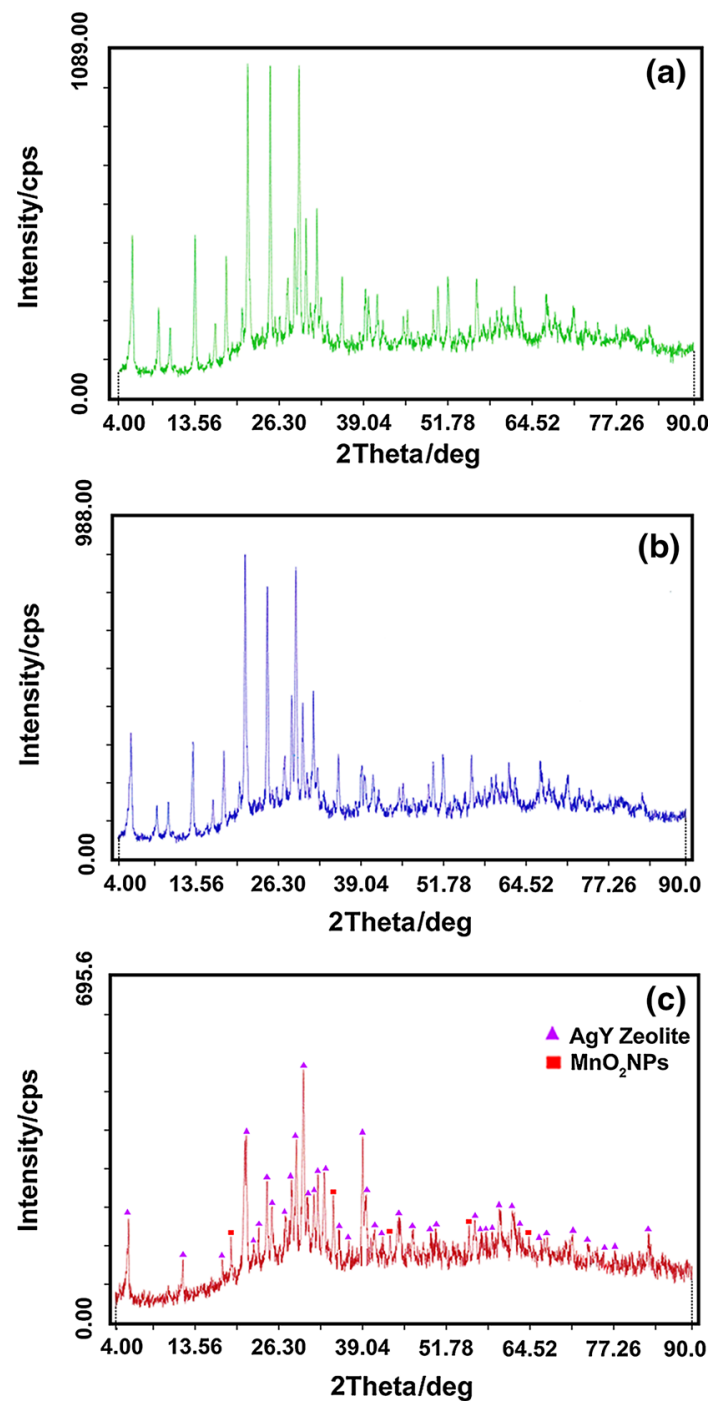

Fig. 3 XRD patterns of the catalyst samples: a NaY zeolite, b AgY zeolite and c $20 \mathrm{wt} \% \mathrm{MnO}_{2} \mathrm{NPs}-\mathrm{AgY}$ zeolite

line broadening of the peak using Debye-Scherrer equation (Patterson 1939)

$d=\frac{0.94 \lambda}{\beta \cos \theta}$

where $d$ is the crystal size, $\lambda$ is the wavelength of X-ray source, $\beta$ is the full width at half maximum (FWHM) and $\theta$ is Bragg diffraction angle. Using this equation, the average crystalline size is estimated to be $41 \mathrm{~nm}$. The crystalline sizes obtained from XRD measurement are consistent with the results from the SEM study.

\section{AAS analysis}

The amounts of silver and manganese elements in the nanocomposite catalyst were determined through elemental analysis by atomic absorption spectrometry (AAS). 
Two series of standard solutions with concentrations of 1-6 and 2-8 ppm were prepared for silver and manganese species, respectively, then were measured by AAS and the corresponding calibration curves were drawn. A nanocomposite solution of known mass was injected to AAS, and silver and manganese elements were measured by the related hollow cathode lamps. After that, through interpolation and known concentrations of standard solutions, the concentrations of the elements were obtained. Subsequently, given the apparent weight of the nanocomposite and the molecular weights of the elements, their weight percentages were calculated. The results revealed that the amounts of these elements were 10 and $20 \mathrm{wt} \%$, respectively.

\section{FTIR study}

The characterization of the prepared nanocomposite catalyst along with the Y-type zeolite precursors was further surveyed by FTIR spectra as plotted in Fig. 4. All three assynthesized samples have similar vibrational frequencies of the zeolite lattice in the range between 400 and $4,000 \mathrm{~cm}^{-1}$ that achieve structural information on Y-type zeolites. These vibrations are distinct in internal and external terms to describe two building units within the zeolite $\mathrm{Y}$ framework; networks formed by $\mathrm{TO}_{4}(\mathrm{~T}=\mathrm{Si}$ or $\mathrm{Al})$ with tetrahedra corners and linkages between them such as double six-membered ring (D6R) structures (so-called hexagonal prisms in X and Y-type zeolites (Auerbach et al. 2003). Below, the average amounts of three peaks representing $\mathrm{NaY}, \mathrm{AgY}$ and $\mathrm{MnO}_{2} \mathrm{NPs}-\mathrm{AgY}$ are given. For all three zeolite parts, vibrations can be observed near 462 and $562 \mathrm{~cm}^{-1}$ that are, respectively assigned to the bending vibration of $\mathrm{T}-\mathrm{O}$ in insensitive internal $\mathrm{TO}_{4}$ tetrahedral units and the vibration of one ring against the other in D6R external linkage assigned to zeolite $\mathrm{Y}$ in the literature (Rasouli et al. 2012a, b). The peaks at 676 and $754 \mathrm{~cm}^{-1}$ are attributed to the external linkage and $\mathrm{O}-\mathrm{T}-\mathrm{O}$ internal tetrahedral symmetrical stretching vibrations. Furthermore, the peaks at $987-988 \mathrm{~cm}^{-1}$ are corresponding to O-T-O internal tetrahedral asymmetrical stretching vibrations, whereas the peak at $1,065 \mathrm{~cm}^{-1}$ is due to the vibrations related to the external linkage asymmetrical stretching between tetrahedral. In the $\mathrm{O}-\mathrm{H}$ stretching region, infrared spectra of zeolites provide a wealth of information on hydroxyl groups attached to zeolite structures. The hydroxyl groups are important for the chemistry of zeolites (Jentys and Lercher 2001). Accordingly, the peaks around 1,644 and $3,500 \mathrm{~cm}^{-1}$ are assigned to $\mathrm{H}-\mathrm{O}-\mathrm{H}$ bending and
O-H bonding (hydroxyl groups) vibrations of Y-type zeolite structures, respectively. Comparing Fig. 4a, b confirms that slight shifts have occurred in the bands of bending, bonding and stretching vibrations of AgY zeolite compared with the original $\mathrm{NaY}$ zeolite, which tends to lend further support to the idea that the ion exchange modification of $\mathrm{NaY}$ zeolite by silver ion has a very little influence on the chemical structure of the zeolite framework. On the other hand, Fig. 4c demonstrates some new peaks related to the synthesized loaded $\mathrm{MnO}_{2} \mathrm{NPs}$. The adsorption peak at $578 \mathrm{~cm}^{-1}$ is corresponding to $\mathrm{Mn}-\mathrm{O}$ bond. The peaks around 1,437 and $3,398 \mathrm{~cm}^{-1}$ are attributed to $\mathrm{H}-\mathrm{O}-\mathrm{H}$ bending and $\mathrm{O}-\mathrm{H}$ bonding (hydroxyl groups) vibrations of the nanoparticles.

To further realize the adsorption and degradation reactions of OSDEMP, the FTIR spectrum of the nanocomposite was also surveyed after the reaction. As illustrated in Fig. 4d, some new significant absorption peaks appeared at $871,1,147,1,279,1,345$ and $3,372 \mathrm{~cm}^{-1}$. The absorption peaks at 841 and $1,147 \mathrm{~cm}^{-1}$ are corresponding to the $\mathrm{C}-$ $\mathrm{C}, \mathrm{C}-\mathrm{S}$ and $\mathrm{M}-\mathrm{S}-\mathrm{C}, \mathrm{C}-\mathrm{O}-\mathrm{P}$ bonds, respectively. The characteristic peaks in the regions of 1,279 and $1,345 \mathrm{~cm}^{-1}$ are related to the $\mathrm{P}=\mathrm{O}$ and $\mathrm{O}-\mathrm{P}-\mathrm{O}$ bonds, respectively which are supposed to appear as a result of hydrolysis process. These observed IR data lead to an understanding of the adsorption and reaction of OSDEMP on the surface of catalyst. It was also found that this catalyst could be regenerated for reuse.

\section{GC and GC-MS analyses}

The decontamination reactions of OSDEMP as organophosphorous pollutant were studied and evaluated on the surface of nanocomposite catalyst at room temperature, and the progresses were monitored by GC-FID analysis. To accede maximum efficiency, the effects of different solvents and time intervals were investigated. The GC chromatograms, area under curve (AUC) data and results under different conditions are summarized in Figs. 5, 6 and Table 1. As denoted in the chromatograms, isopropanol, chloroform, $n$-heptane, $n$-octane and OSDEMP are diagnosed at retention times of 1.2, 2.5, 6, 9.4 and $14.7 \mathrm{~min}$, respectively. To calculate the amounts of decontaminated organo-phosphorous pesticide, the integrated AUC data of the two samples, OSDEMP and $n$-octane as internal standard have been given for all times and solvents. Subsequently, the ratios of the integrated data (integrated AUC of OSDEMP/integrated AUC of $n$-octane) were determined and the results are shown in Table 1 . The experiments were 
Fig. 4 FTIR spectra of the catalyst samples: $a \mathrm{NaY}$ zeolite, $b$ AgY zeolite, $c 20 \mathrm{wt} \%$ $\mathrm{MnO}_{2} \mathrm{NPs}-\mathrm{AgY}$ zeolite after and $d$ before the decontamination reaction
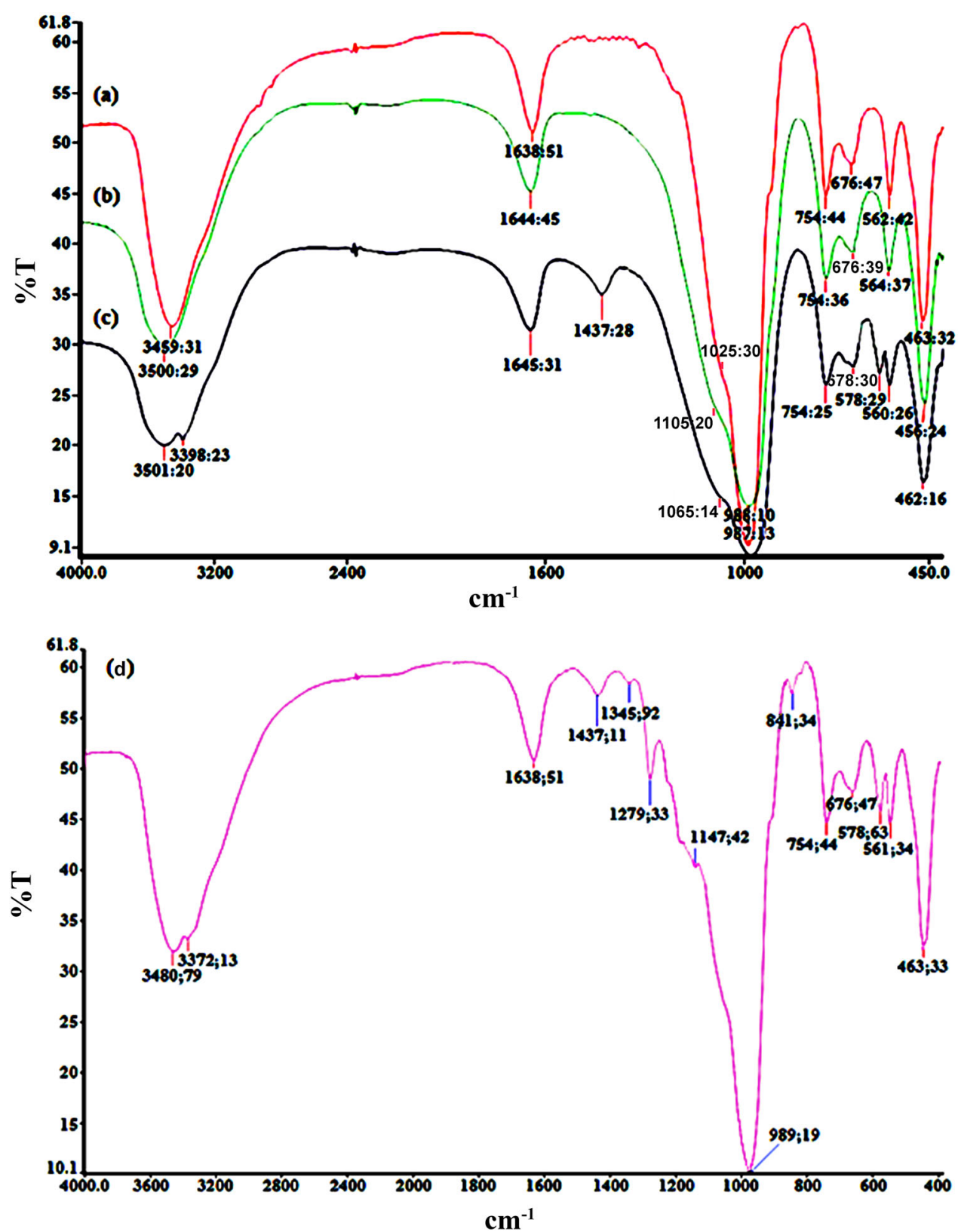

performed at different time intervals of 0 and $8 \mathrm{~h}$. With increasing the shaking time, a decreasing trend in the AUC amounts of OSDEMP was observed until $8 \mathrm{~h}$. These results confirm that the catalyst is perfectly capable of decontaminating OSDEMP (100\%) in $n$-heptane after 8 h. On the other hand, the decontamination data were lower for chloroform and isopropanol as solvents. In spite of the fact that the transition state must be involved in the polar reaction, polar solvent hinders the reaction's progress. It could be construed from GC analysis that polar solvent can compete with the reaction sites presented on the surface of the catalyst including Lewis $\left(\mathrm{Mn}^{+4}\right)$ and Bronsted [hydroxyl groups (Mn-OH)] acid sites. In particular, blocking of Lewis acid sites would hinder the coordination of OSDEMP. Since isopropanol is considered as a strong hindrance to the reaction, this points out the fact that isopropanol simply blocks access to the surface of the catalyst. 


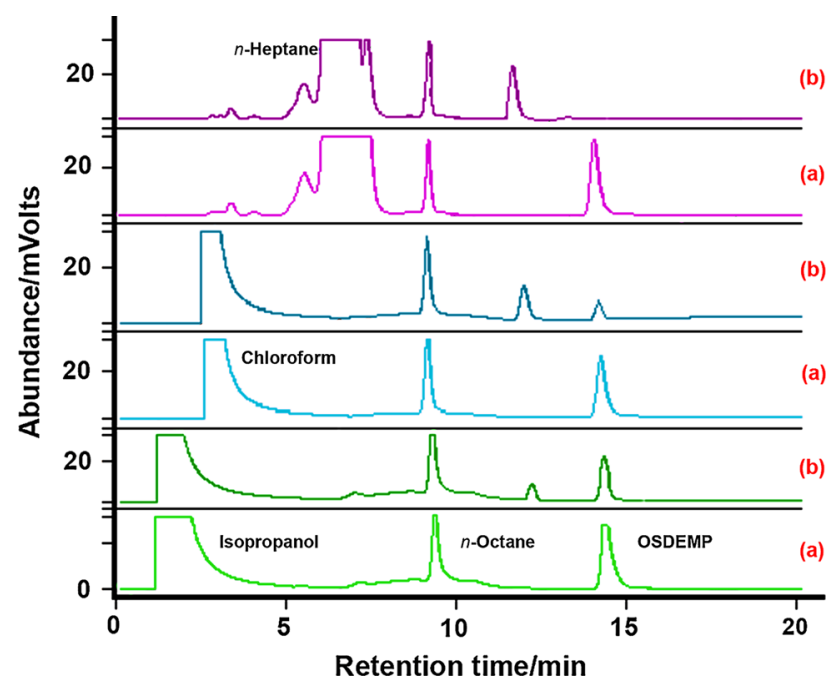

Fig. 5 GC chromatograms of decontamination reactions in different solvents, $a$ before and $b$ after the reaction

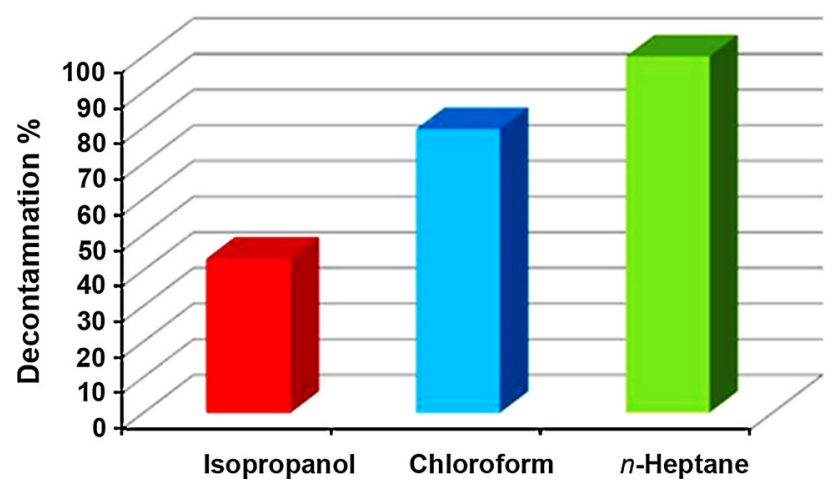

Fig. 6 The curve of the amount of decontaminated OSDEMP in different solvents after $8 \mathrm{~h}$

Table 1 GC results for the decontamination of OSDEMP on the surface of $20 \mathrm{wt} \% \mathrm{MnO}_{2} \mathrm{NPs}-\mathrm{AgY}$ zeolite in different solvents after $8 \mathrm{~h}$, (a) before and (b) after the reaction

\begin{tabular}{lllll}
\hline Solvent & Sample & $\begin{array}{l}\text { AUC/n- } \\
\text { Octane(1) }\end{array}$ & $\begin{array}{l}\text { AUC/ } \\
\text { OSDEMP(2) }\end{array}$ & $\begin{array}{l}\text { Ratio(AUC } \\
\text { 2/AUC 1) }\end{array}$ \\
\hline Isopropanol & a & 283,511 & 275,572 & 0.972 \\
& b & 288,964 & 159,594 & 0.5523 \\
Chloroform & a & 355,873 & 246,834 & 0.7441 \\
& b & 318,629 & 203,112 & 0.1522 \\
n-Heptane & a & 350,456 & 348,462 & 0.9943 \\
& b & 345,280 & 0 & 0 \\
\hline
\end{tabular}

AUC Area under curve
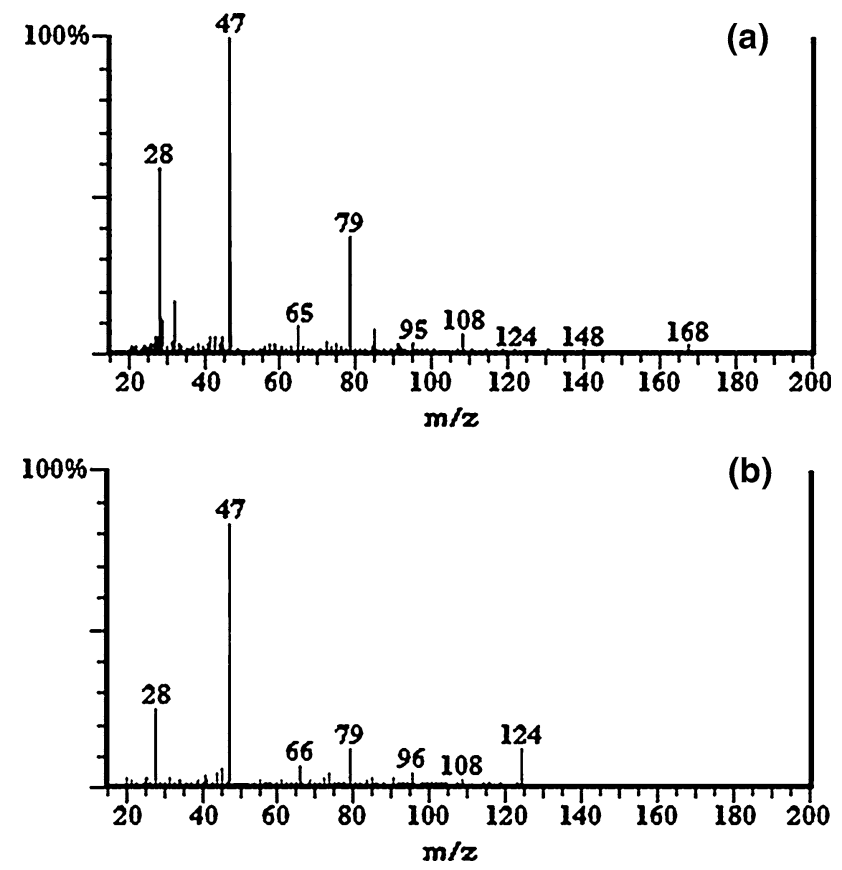

Fig. 7 GC-MS analysis and mass spectra of a organo-phosphorous pesticide OSDEMP and $\mathbf{b}$ its decontamination product EMPA

Once OSDEMP reacted on the surface of $20 \mathrm{wt} \%$ $\mathrm{MnO}_{2} \mathrm{NPs}-\mathrm{AgY}$ zeolite, the identification and quantification of the decontamination product were followed by GCMS analysis. It is evident from mass spectrum data that the formation of ethyl methyl phosphonic acid (EMPA) (m/z values at 28-124) emphasizes the role of hydrolysis reaction in the degradation of OSDEMP $(\mathrm{m} / \mathrm{z}$ values at 28-168), thereby rendering its less toxic product (Fig. 7). This new product has a retention time at about $11.7 \mathrm{~min}$.

Mechanism of the decontamination procedure

After the investigation of the reaction between OSDEMP and $20 \mathrm{wt} \% \mathrm{MnO}_{2} \mathrm{NPs}-\mathrm{AgY}$ zeolite composite catalyst, a mechanism scheme reflecting the decontamination process (adsorption/degradation) is proposed based on which two routes along with the roles of manganese dioxide-ethyl methyl phosphonate $\left(\mathrm{MnO}_{2}-\mathrm{EMPA}\right)$ and silver-ethyl methyl phosphonate (Ag-EMPA) as intermediates, the cleavage of the P-S bond in OSDEMP and the formation of EMPA as the hydrolysis product are predicted (Scheme 2). OSDEMP molecule contains bivalent sulfur atom that possesses two lone pairs of electrons. At first, slight amounts of deionized water in a $5: 1(\mathrm{v} / \mathrm{v})$ ratio were added to OSDEMP samples to activate Bronsted acid sites over the surface of nanocomposite and to accelerate the 
Scheme 2 Proposed reaction mechanisms of the decontamination of OSDEMP on the surface of the $20 \mathrm{wt} \%$ $\mathrm{MnO}_{2} \mathrm{NPs}-\mathrm{AgY}$ zeolite; a manganese and $\mathbf{b}$ silver as reactive sites

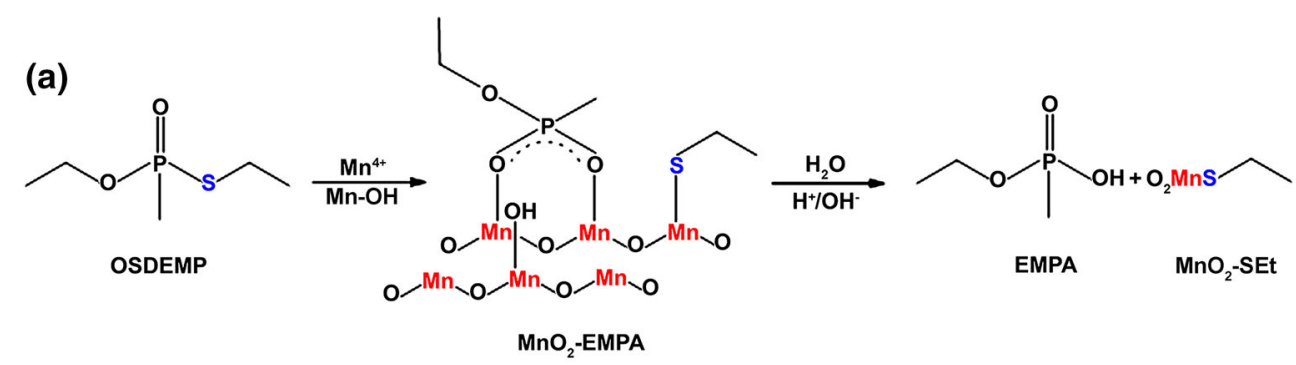

(b)

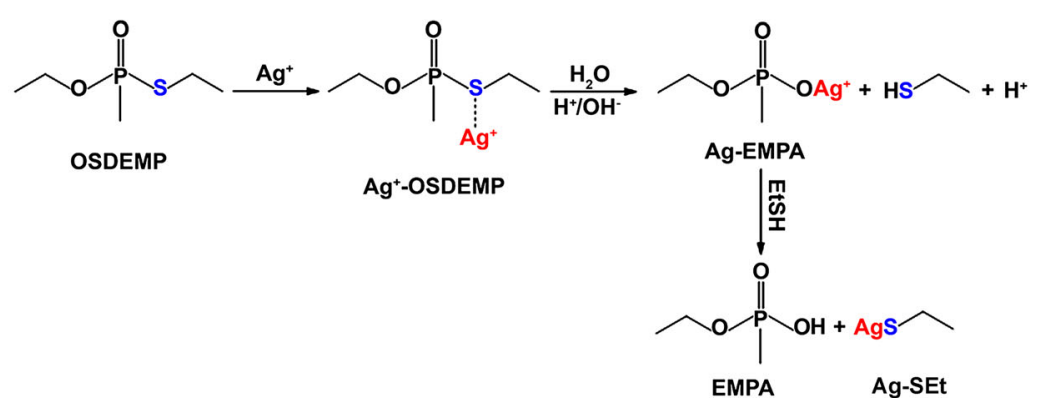

degradation of OSDEMP. Positive water effect was also observed in the degradation of sulfur mustard agent in the literature (Wagner et al. 2001; Sambur et al. 2008; Tang et al. 2008). Besides, there are a large number of strong Lewis acid sites providing suitable space to bind to the pesticide. Residual surface $-\mathrm{OH}$ groups together with Lewis acid sites give reactivity and add to the rich surface chemistry exhibited by nano-structured metal oxides and porous zeolite materials as previously mentioned for nanoparticles of $\mathrm{MgO}, \mathrm{CaO}, \mathrm{SrO}, \mathrm{BaO}, \mathrm{Al}_{2} \mathrm{O}_{3}, \mathrm{TiO}_{2}, \mathrm{Fe}_{2} \mathrm{O}_{3}$ and $\mathrm{ZnO}$ and $\mathrm{NaY}$ zeolites (Prasad et al. 2011; Richter et al. 2002; Wong et al. 2008). Both Bronsted and Lewis approaches are involved in the surface activity of the typical $\mathrm{MnO}_{2}-\mathrm{AgY}$ nanocomposite. Furthermore, high surface area and the reactive sites tailored in the form of edge/ corner defects and unusual lattice planes within $\mathrm{MnO}_{2} \mathrm{NPs}$ on the one hand, and the catalysis potential of silver ion exchanged with the surface of zeolite for the abstraction of sulfur atom in OSDEMP structure on the other hand, help to form the surface bound species and facilitate accelerated catalytic hydrolysis of the pesticide in different ways (Wagner and Bartram 1999; Prasad et al. 2009; Mahato et al. 2011).
In route (a), OSDEMP molecule reacts with Lewis acid sites $\left(\mathrm{Mn}^{4+}\right)$ and Bronsted acid sites [hydroxyl groups $(\mathrm{Mn}-\mathrm{OH})]$ presented on the surface of the nanocomposite catalyst through two phosphoryl oxygen and two manganese atoms to form surface bound $\mathrm{Mn}-\mathrm{O}-$ P-O-Mn species (Prasad et al. 2011). The interaction follows with the cleavage of $\mathrm{P}-\mathrm{S}$ bond in OSDEMP and bonding between the sulfur atom and the surface $\mathrm{MnO}_{2}$ that leads to the formation of $\mathrm{MnO}_{2}$-EMPA as an intermediate and manganese dioxide ethylmercaptide $\left(\mathrm{MnO}_{2}-\mathrm{SEt}\right)$. Subsequently, adsorption of a proton produces EMPA as final product. On the other hand, in route (b), the electrophilic attack of positive silver $\left(\mathrm{Ag}^{+}\right)$ of the zeolite structure (Lewis acid site) on sulfur atom makes OSDEMP adsorb onto the surface of the catalyst $\left(\mathrm{Ag}^{+}\right.$-OSDEMP). Then, the nucleophilic attack of water on the phosphorous atom results in the cleavage of the $\mathrm{P}-\mathrm{S}$ bond to eliminate the EtSH group (which is highly volatile and easily escapes from the reaction mixture). This leads to the formation of Ag-EMPA which acts as an intermediate. Simultaneously, the sulfur atom of EtSH group binds to the silver atom through nucleophilic attack followed by the elimination of a proton, 
which produces EMPA as hydrolysis product and AgSEt (silver ethylmercaptide) as a by-product.

\section{Conclusion}

In the present study, we produced $20 \mathrm{wt} \% \mathrm{MnO}_{2} \mathrm{NPs}-\mathrm{AgY}$ zeolite composite catalyst aiming to convert OSDEMP as an organo-phosphorous pesticide into a non-toxic or less toxic product. The characterization data were obtained by SEM, XRD, AAS and FTIR measurements. In addition, GC and GC-MS analyses provided valuable information about the decontamination efficiency of OSDEMP molecule on the surface of $20 \mathrm{wt} \% \mathrm{MnO}_{2} \mathrm{NPs}-\mathrm{AgY}$ zeolite. Adsorption, degradation and hydrolysis reactions were evaluated in different solvents and time intervals. The results demonstrated that OSDEMP was decontaminated perfectly $(100 \%)$ in $n$-heptane solvent after $8 \mathrm{~h}$. The less toxic degradation product, i.e., ethyl methyl phosphonothioic acid (EMPA), was also identified.

Acknowledgments The authors are grateful to Young Researchers and Elite Club, Ahvaz and Karaj branches.

\section{References}

Al-Qurainy F, Abdel-Megeed A (2009) Phytoremediation and detoxification of two organophosphorous pesticides residues in Riyadh area. World Appl Sci J 6:987-998

Auerbach SM, Carrado KA, Dutta PK (2003) Handbook of zeolite science and technology. Marcel Dekker Inc., New York

Bagheri H, Ayazi Z, Aghakhani A, Alipour N (2012) Polypyrrole/ polyamide electrospun-based sorbent for microextraction in packed syringe of organophosphorous pesticides from aquatic samples. J Sep Sci 35:114-120

Barata C, Solayan A, Porte C (2004) Role of B-esterases in assessing toxicity of organophosphorus (chlorpyrifos, malathion) and carbamate (carbofuran) pesticides to Daphnia magna. Aquat Toxicol 66:125-139

Barlocher CH, Meier WM, Olson DH (2001) Atlas of zeolite framework types, Rev edn. Elsevier, Amsterdam

Bartram PW, Wagner GW (2003) Decontamination method for toxic chemical agents. US Patent, No 6, 537, 382

Cao H, Suib SL (1994) Highly efficient heterogeneous photooxidation of 2-propanol to acetone with amorphous manganese oxide catalysts. J Am Chem Soc 116:5334-5342

Chen D, Wang J, Xu Y, Li D (2012) A pure shear mode ZnO film resonator for the detection of organophosphorous pesticides. Sens Actuators B 171-172:1081-1086
Diurak L, Kazanicif M (2001) Effect of some organophosphorus insecticides on soil microorganisms. Turk J Biol 25:51-58

Elzey S, Mubayib A, Larsen SC, Grassian VH (2008) FTIR study of the selective catalytic reduction of $\mathrm{NO}_{2}$ with ammonia on nanocrystalline $\mathrm{NaY}$ and $\mathrm{CuY}$. J Mol Catal A: Chem 285:48-57

Feeley JS, Sachtler WMH (1991) Enhanced reductibility of Ni and $\mathrm{Ni}+\mathrm{Pd}$ in zeolite Y: blocking of small cages with $\mathrm{Ca}^{2+}$ or $\mathrm{Mg}^{2+}$ ions. Catal Lett 9:377-386

Gupta VK, Nayak A (2012) Cadmium removal and recovery from aqueous solutions by novel adsorbents prepared from orange peel and $\mathrm{Fe}_{2} \mathrm{O}_{3}$ nanoparticles. Chem Eng J 180:81-90

Gupta VK, Jain R, Malathi S, Nayak A (2010a) Adsorptiondesorption studies of indigocarmine from industrial effluents by using deoiled mustard and its comparison with charcoal. J Colloid Interface Sci 348:628-633

Gupta VK, Rastogi A, Nayak A (2010b) Adsorption studies on the removal of hexavalent chromium from aqueous solution using a low cost fertilizer industry waste material. J Colloid Interface Sci 342:135-141

Gupta VK, Jain R, Nayak A, Agarwal A, Shrivastava M (2011) Removal of the hazardous dye-tartrazine by photodegradation on titanium dioxide surface. Mater Sci Eng C 31:1062-1067

Gupta VK, Kumar R, Nayak A, Saleh TA, Barakat MA (2013) Adsorptive removal of dyes from aqueous solution onto carbon nanotubes: a review. Adv Colloid Interface Sci 193-194:24-34

Howard PH, Sage GW, Jarvis WF, Gray DA (1990) Handbook of environmental fate and exposure data for organic chemicals, vol 4. Lewis Publishers Inc, Chelsea, p 578

Huang YY (1974) Adsorption in AgX and AgY zeolites by carbon monoxide and other simple molecules. J Catal 32:482-491

Jentys A, Lercher JA (2001) Characterization of zeolites. In: van Bekkum H, Flanigen EM, Jacobs PA, Jensen JC (eds) Introduction to zeolite science and practice. Elsevier, Amsterdam, p 345

Jiao F, Frei H (2010) Nanostructured cobalt and manganese oxide clusters as efficient wateroxidation catalysts. Energy Environ Sci 3:1018-1027

Kanan SM, Tripp CP (2001) An infrared study of adsorbed organophosphonates on silica: a prefiltering strategy for the detection of nerve agents on metal oxide sensors. Langmuir 17:2213-2218

Khajeh M, Laurent S, Dastafkan K (2013) Nanoadsorbents: classification, preparation, and applications (with emphasis on aqueous media). Chem Rev 113:7728-7768

Khatamian M, Alaji Z, Khandar AA (2011) Synthesis and characterization of polycrystalline $\mathrm{ZnO} / \mathrm{HZSM}-5$ nanocomposites. J Iran Chem Soc 8:44-54

Kim SO, Park ED, Ko EY (2006) Zeolite and sorbent for desurfurization and method of preparing the same. US Patent, No 016, $25,57, \mathrm{~A} 1$

Koivula R, Pakarinen J, Sivenius M, Sirola K, Harjula R, Paatero E (2009) Use of hydrometallurgical wastewater as a precursor for the synthesis of cryptomelane-type manganese dioxide ion exchange material. Sep Purif Technol 70:53-57

Knagge K, Johnson M, Grassian VH, Larsen SC (2006) Adsorption and thermal reaction of DMMP in nanocrystalline $\mathrm{NaY}$. Langmuir 22:11077-11084 
Li Q, Wang X, Yuan D (2009) Solid-phase extraction of polar organophosphorous pesticides from aqueous samples with oxidized carbon nanotubes. J Environ Monit 11:439-444

Liu R, Liua H, Qiang Z, Qu J, Li G, Wang D (2009) Effects of calcium ions on surface characteristics and adsorptive properties of hydrous manganese dioxide. J Colloid Interface Sci 331:275-228

Mahato TH, Prasad GK, Singh B, Batra K, Ganesan K (2010) Mesoporous manganese oxide nanobelts for decontamination of sarin, sulfur mustard and chloro ethyl ethyl sulfide. Microporous Mesoporous Mater 132:15-21

Mahato TH, Singh B, Srivastava AK, Prasad GK, Srivastava AR, Ganesan K, Vijayaraghavan R (2011) Effect of calcinations temperature of $\mathrm{CuO}$ nanoparticle on the kinetics of decontamination and decontamination products of sulphur mustard. J Hazard Mater 192:1890-1895

Meng Q, Doetschman DC, Rizos AK, Lee MH, Schulte JT, Spyros A, Kanyi CW (2011) Adsorption of organophosphates into microporous and mesoporous $\mathrm{NaX}$ zeolites and subsequent chemistry. Environ Sci Technol 453:3000-3005

Mitchell MB, Sheinker VN, Tesfamichae ENG, Nunley M (2003) Decomposition of dimethyl methylphosphonate (DMMP) on supported cerium and iron co-impregnated oxides at room temperature. J Phys Chem B 107:580-586

Moussavi G, Hosseini H, Alahabadi A (2013) The investigation of diazinon pesticide removal from contaminated water by adsorption onto $\mathrm{NH}_{4} \mathrm{Cl}$-induced activated carbon. Chem Eng J 214:172-179

Munro NB, Talmage SS, Griffin GD, Waters LC, Watson AP, King JF, Hauschild V (1999) The sources, fate, and toxicity of chemical warfare agent degradation products. Environ Health Perspect 107:933-974

Oliveira MLM, Miranda AAL, Barbosa CMBM, Cavalcante CL Jr, Azevedo DCS, Rodriguez-Castellon E (2009) Adsorption of thiophene and toluene on $\mathrm{NaY}$ zeolites exchanged with $\mathrm{Ag}(\mathrm{I})$, $\mathrm{Ni}(\mathrm{II})$ and $\mathrm{Zn}(\mathrm{II})$. Fuel 88:1885-1892

Padron-Sanz C, Halko R, Sosa-Ferrera Z, Santana-Rodryguez JJ (2005) Combination of microwave assisted micellar extraction and liquid chromatography for the determination of organophosphorous pesticides in soil samples. J Chromatogr A 1078:13-21

Patterson A (1939) The Scherrer formula for X-ray particle size determination. Phys Rev 56:978-982

Patterson HH (2006) Development of a rapid decontamination system for nerve agents. US Army Research, NC OMB, No 0704-0188

Paukku Y, Michalkova A, Leszczynski J (2008) Adsorption of dimethyl methylphosphonate and trimethylphosphate on calcium oxide: an ab initio study. Struct Chem 19:307-320

Prasad GK (2010) Decontamination of 2-chloro ethyl phenyl sulfide using mixed metal oxide nanocrystals. J Sci Ind Res 69:835-840

Prasad GK, Singh B, Ganesan K, Batra A, Kumeria T, Gutch PK, Vijayaraghavan R (2009) Modified titania nanotubes for decontamination of sulfur mustard. J Hazard Mater 167:1192-1197

Prasad GK, Ramacharyulu PVRK, Singh B (2011) Nanomaterial based decontaminates against chemical warfare agents. J Sci Ind Res 70:91-104

Qi F, Hirofumi K, Kenta O (1999) Manganese oxide porous crystals. J Mater Chem 9:319-333

Qi R, Wang Y, Chen J, Li J, Zhu S (2007) Removing thiophenes from n-octane using PDMS-AgY zeolite mixed matrix membranes. J Membr Sci 295:114-120
Rasouli M, Yaghobi N, Chitsazan S, Sayyar MH (2012a) Adsorptive separation of meta-xylene from C8 aromatics. Microporous Mesoporous Mater 90:1407-1415

Rasouli M, Yaghobi N, Chitsazan S, Sayyar MH (2012b) Effect of nanocrystalline zeolite Na-Y on meta-xylene separation. Microporous Mesoporous Mater 152:141-147

Richter M, Berndt H, Eckelt R, Schneider M, Fricke R (1999) Zeolitemediated removal of $\mathrm{NOx}$ by $\mathrm{NH}_{3}$ from exhaust streams at low temperature. Catal Today 54:531-545

Richter M, Trunschke A, Bentrup U, Brzezinka KW, Schreier E, Schneider M, Pohl MM, Fricke R (2002) Selective catalytic reduction of nitric oxide by ammonia over egg-shell $\mathrm{MnO}_{x} / \mathrm{Na}-\mathrm{Y}$ composite catalysts. J Catal 206:98-113

Rusu CN, Yates JT (2000) Adsorption and decomposition of dimethyl methylphosphonate on $\mathrm{TiO}_{2}$. J Phys Chem B 104:12992-12998

Sambur JB, Doetschman DC, Yang SW, Schulte JT, Jones BR, DeCoste JB (2008) Multiple effects of the presence of water on the nucleophilic substitution reactions of NaX Faujasite zeolite with dimethyl methylphosphonate (DMMP). Microporous Mesoporous Mater 112:116-124

Seidel A, Kampf G, Schmidt A, Boddenberg B (1998) Zeolite ZnY catalysts prepared by solid-state ion exchange. Catal Lett $51: 213-218$

Shen YF, Zerger RP, DeGuzman RN, Suib SL, McCurdy L, Potter DI, O'Young CL (1993) Manganese oxide octahedral molecular sieves: preparation, characterization, and applications. Science 23:511-515

Shen HY, Zhu Y, Wen XE, Zhuang YM (2007) Preparation of $\mathrm{Fe}_{3} \mathrm{O}_{4^{-}}$ C18 nano-magnetic composite materials and their cleanup properties for organophosphorous pesticides. Anal Bioanal Chem 387:2227-2237

Singh R, Gutch PK, Acharya J, Prabha S (2011) Detoxification of O,S-diethyl methylphosphonothiolate (OSDEMP), a simulant of $\mathrm{VX}$, by $\mathrm{N}, \mathrm{N}$-dichlorourethane an effective decontamination agent. Indian J Chem B 50:1504-1509

Stout SC, Larsen SC, Grassian VH (2007) Adsorption, desorption and thermal oxidation of 2-CEES on nanocrystalline zeolites. Microporous Mesoporous Mater 100:77-86

Tang H, Cheng Z, Zhu H, Zuo G, Zhang M (2008) Effect of acid and base sites on the degradation of sulfur mustard over several typical oxides. Appl Catal B 79:323-333

Tomašević A, Kiss E, Petrović S, Mijin D (2010) Study on the photocatalytic degradation of insecticide methomyl in water. Desalination 262:228-234

Trouve A, Batonneau-Gener I, Valange S, Bonne M, Mignard S (2012) Tuning the hydrophobicity of mesoporous silica materials for the adsorption of organic pollutant in aqueous solution. J Hazard Mater 201-202:107-114

Wagner GW, Bartram PW (1999) Reactions of VX, HD, and their simulants with $\mathrm{Na}-\mathrm{Y}$ and $\mathrm{Ag}-\mathrm{Y}$ zeolites desulfurization of VX on Ag-Y. Langmuir 15:8113-8118

Wagner GW, Bartram PW, Koper O, Klabunde KJ (1999) Reactions of VX, GD, and HD with nanosize MgO. J Phys Chem B 103:3225-3228

Wagner GW, Koper OB, Lucas E, Decker S, Klabunde KJ (2000) Reactions of $\mathrm{VC}, \mathrm{GC}$, and $\mathrm{HD}$ with nanosize $\mathrm{CaO}$ : autocatalytic dehydrohalogenation of HD. J Phys Chem B 107:5118-5123

Wagner GW, Porcell LR, O'Connor RJ, Munavalli S, Carnes CL, Kapoor PN, Klabunde KJ (2001) Reactions of VX, GB, GD, and 
$\mathrm{HD}$ with nanosize $\mathrm{Al}_{2} \mathrm{O}_{3}$. Formation of aluminophosphonates. J Am Chem Soc 123:1636-1644

Wang AJ, Zhang PP, Li YF, Feng JJ, Dong WJ, Liu XY (2011) Hydrogen peroxide sensor based on glassy carbon electrode modified with $\beta$-manganese dioxide nanorods. Microchim Acta $175: 31-37$

Wong CT, Abdullah AZ, Bhatia S (2008) Catalytic oxidation of butyl acetate over silver-loaded zeolites. J Hazard Mater 157:480-489

Yan W, Kim JY, Xing W, Donavan KC, Ayvazian T, Penner RM (2012) Lithographically patterned gold/manganese dioxide core/ shell nanowires for high capacity, high rate, and high cyclability hybrid electrical energy storage. Chem Mater 24:2382-2390

Yang YC, Bake JA, Ward JR (1992) Decontamination of chemical warfare agents. Chem Rev 92:1729-1743

Yang SW, Doetschman DC, Schulte JT, Sambur JB, Kanyi CW, Fox JD, Kowenje CO, Jones BR, Sherma ND (2006) Sodium X-type faujasite zeolite decomposition of dimethyl methylphosphonate (DMMP) to methylphosphonate: nucleophilic zeolite reactions I. Microporous Mesoporous Mater 92:56-60 